\title{
Comparative Study on Mental Health among Badminton Players and Table Tennis Players of the Kalaburagi District in India
}

\author{
H.S. Jange \\ Asst. Director, Dept. of Physical Education \\ Gulbarga University \\ Gulbarga, Karantaka, India
}

\begin{abstract}
Mental health can be defined as a state of wellbeing that makes every individual realizes his or her own potential to cope with the normal stress of life, so as to work productively and fruitfully to make contribution to the community. The purpose of this study is to examine the mental health level between the Badminton and Table Tennis Players of Gulbarga University. The samples used for this study consist of 50 male badminton players and 50 Male table tennis players of the Kalaburagi District. Dr. Jagadish and Dr. A. K. Srivastava developed mental Health scale used in this study. Data were collected from the Badminton and Table Tennis players of Kalburagi District. Just before the administration of the tests, the players were informed about the importance of mental health. The results of this study shows that table tennis players have more mental health compare to the badminton players. In this study, it was discovered that table tennis and badminton keeps the players well, strong, motivated, enthusiastic, and young. It also helps to lower depression, anxiety, stress, and increase the self-esteem, and mental health. So to enhance mental health, individual must be involved in physical activities. Exercising regularly if it is in small amount is a major key to good health. Taking part in sports is an excellent way to strengthen your heart and all your other muscles while having lots of fun. People involved in sports practice three times a week, or more and often several times a day, to keep their muscles in top physical condition. It is also known that sports have positive effect on mental health, stress level, and mood; so mental health is very important for the success of people involved in sports. Therefore, it is concluded that table tennis players have better mental health compare to badminton players. This study will help physical educators and coaches to give importance of mental health among players, so they can perform better in competition.
\end{abstract}

Keywords-mental health, anxiety, table tennis, badminton

\section{INTRODUCTION}

Mental health refers to the ability to be balanced in one's daily living, and the ability to face and balance the reality of life (Bhatia, 1982). Mental health is a complex phenomenon that depends on a set of familiarly personal, psychological and social variables. Mental health is important to the physical health of an individual to make him complex with balanced mental disposition, so as to be able to cope with life more effectively and productively. For an individual, good mental health depends on the good state of both mind and body. Each exerts a direct influence on the other, but owing to the power of matter, good mental health is of supreme importance. According to Hadfield (1952), mental health is the harmonious functioning of the whole personality of a person.

Tennis is a racquet sport that can be played individually against a single opponent (singles), or between two teams of two players each (doubles). Each player uses a racquet that is strung with cord to strike a hollow rubber ball covered with felt over or around a net, into the opponent's court. The objective of the game is to play the ball in a way that the opponent unable to play a good return. The opponent who is unable to play a good return will not gain a point, while the other opponent will. Tennis is an Olympic sport and it is played at all levels of society and all ages. The sport can be played by anyone including people sitting on wheelchair.

The modern game of tennis originated from Birmingham, England in the late 19th century as "lawn tennis". Tennis is played by millions of recreational players and is also a popular worldwide spectator sport. The four Slam tournaments (also referred to as the "Majors") are especially popular: the Australian Open played on hard courts, the French Open played on red clay courts, Wimbledon played on grass courts, and the US Open played also on hard court. Table tennis, also known as ping pong is a sport which two or four players hit a lightweight ball back and forth across a table using a small, round bat. The game takes place on a hard table divided by a net. Except for the initial serve, players must allow the ball played towards them bounce only once on their side of the table, and must return it so that it bounces on the opposite side. Points are scored when a player fails to return the ball within the rules. Play is fast and demands quick reactions. Spinning the ball alters its trajectory, therefore limiting an opponent's option which gives the hitter a great advantage. Spinning the ball makes the hitter has a better chance of scoring if the spin is successful.

Table tennis is governed by the worldwide organization International Table Tennis Federation (ITTF), founded in 1926. ITTF currently have 220 member associations. The table tennis official rules are specified in the ITTF handbook.

Since 1988, table tennis has been an Olympic sport with several event categories. In particular, from 1988 till 2004, there were men's singles, women's singles, men's doubles and women's doubles; but since 2008, a team event has been played instead of the doubles.

The Purpose of this study is to examine the level of Mental Health between the Tennis and Table Tennis players of Gulbarga District. 


\section{METHODOLOGY}

The sample used for this study consists of 50 male table tennis players and 50 male lawn tennis players of the Kalburagi District. Mental Health scale developed by Dr. Jagadish and Dr. A. K. Srivastava was used in this study. Data were collected from the table tennis and the lawn tennis players of Gulbarga University who were administered the Mental Health Scale during indoor games competitions. Before the tests were administered, the importance of mental health was discussed with the players.

Table I. Showing the Mental Health of Table Tennis Player AND TENNIS PLAYERS

\begin{tabular}{|c|c|c|c|c|c|}
\hline Players & MEAN & S.D & N & df & t \\
\hline $\begin{array}{c}\text { Table Tennis } \\
\text { Players }\end{array}$ & 95.83 & 6.04 & 50 & \multirow{2}{*}{98} & $8.22^{* *}$ \\
\cline { 1 - 3 } $\begin{array}{c}\text { Lawn Tennis } \\
\text { Players }\end{array}$ & 90.91 & 5.96 & 50 & & \\
\hline
\end{tabular}

**Significant at 0.01 level

\section{RESULTS AND DISCUSSION}

Table tennis players have a mean of 95.83 while lawn tennis players have mean of 90.91. Hence, table tennis players have better mental health compare to lawn tennis players. Sportspeople experience unique pressures in their jobs, and this ranges from scoring goals to winning trophies to facing media scrutiny, and meeting the high expectations of their adoring fans. The managers, coaches, clubs, governing bodies, and player's unions all play a role in supporting sports professionals so they can manage their mental wellbeing at work. Researchers have identified three particular mental health pressure points for professional sports people, coinciding with times of key transition.

\section{CONCLUSION}

In this study, it is concluded that table tennis players have better mental health compare to lawn tennis players. Regular exercise even if it is in small amount is a major key to good health. Involving in sports is an excellent way to strengthen your heart muscles and all other muscles while having a lot of fun. Most people that are involved in sports practice three times a week or more, or several times a day. This helps to keep their muscles in top physical condition and it also have positive effect on mental health, stress level and moods. Mental Health has a lot of importance and huge impact to the success of a sport person. This study will help the physical educators and coaches to discuss the importance of mental health among players so they can perform better in their competition. It has been recommended that Psychological Training must be given to sports persons to enhance their psychological preparation so they can achieve high level in competitions.

\section{ACKNOWLEDGMENT}

I am grateful to the coaches of table tennis and badminton for their help in accomplishment of this study.

\section{REFERENCES}

[1] Bhardwaj, R.L. (2007). Indian Psychological Review, Agra Psychological Research Cell (U.P.) India.

[2] Bhardwaj, R.L. (2008). Behavioural Scientist (Bi. Annual) A publication of the Councial of Behavioural Scientists of India.

[3] Nesse R.M. (2005). Evolutionary Psychology and mental health in David Buss, (Ed.), Handbook of Evolutionary psychology

[4] Shaughnessy, J.J. and Zechemeister, E.B. (1997). Research Methods in Psychology (4th ed.). New York: McGraw-Hill.

www.worldbadminton.net 